Yu. V. Popov, N. V. Nemtseva, K. V. Shcherbakova, V. M. Mokhov, D. N. Nebykov

\title{
STUDY OF THE PROCESSES OF HYDROGENATION OF MONOTERPENES \\ IN THE STEAM-GAS PHASE IN THE PRESENCE \\ OF NICKEL NANOPARTICLES SUPPLIED ON $\gamma-\mathrm{Al}_{2} \mathrm{O}_{3}$
}

\section{Volgograd State Technical University}

Abstract: The process of hydrogenation of natural monoterpenes, such as: $\alpha$-pinene, citronellal, camphene by catalysis by nickel nanoparticles on $\mathrm{Al}_{2} \mathrm{O}_{3}$ in a continuous mode, in the gas phase of the reaction, was studied. It is shown that during the process in the gas phase, the yield of the main product reaches about $90 \%$.

Keywords: catalysis, nickel nanoparticles, supported catalysts, hydrogenation, monoterpenes.

\section{В. В.Чапуркин, С. В.Чапуркин}

\section{О СИНТЕЗЕ 1-ГИДРОПЕРОКСИДОВ ФТОРЗАМЕЩЕННЫХ АРЕНОВ}

\section{Волгоградский государственный технический университет}

E-mail: chapurkin@vstu.ru

Взаимодействием фторзамещенных ароматических карбонильных соединений с гидропероксидом третбутила получены гидроксигидропероксиды, нефторированные аналоги которых не получены из-за их неустойчивости. Синтезированные пероксиды представляют интерес как инициаторы структурирования фторкаучуков.

Ключевые слова: фторзамещенные бензальдегиды, ароматические кетоны, гидропероксид трет-бутила, гидроксигидропероксид, фторкаучуки.

Взаимодействие различных замещенных бензальдегидов с гидропероксидами описано в ряде работ [1]. Как правило, основным продуктом этой реакции являются пероксидные ацетали, тогда как попытки получения пероксидных полуацеталей к успеху не привели, несмотря на варьирование условий реакции (соотношение реагентов, кислотность среды, растворитель, температура).

Ранее авторами было описан синтез фторсодержащих фенил-1-гидроксиал-килпероксидов взаимодействием фторзамещенных бензальдегидов с гидропероксидом трет-бутила [2, 3]. Возможности этого синтеза благоприятствовало наличие сильных электроноакцепторных заместителей, таких как трифторметильная группа и пентафторфенильная группа.

$$
\begin{aligned}
\mathrm{Ar}-\mathrm{CH}=\mathrm{O}+\left(\mathrm{CH}_{3}\right)_{3} \mathrm{COOH} \rightarrow & \mathrm{Ar}-\mathrm{CH}(\mathrm{OH}) \mathrm{OOC}\left(\mathrm{CH}_{3}\right)_{3}
\end{aligned}
$$$$
\mathrm{Ar}=\mathrm{o}-\mathrm{CF}_{3} \mathrm{C}_{6} \mathrm{H}_{4}(1), \mathrm{C}_{6} \mathrm{~F}_{5}
$$

Взаимодействие фторзамещенных бензальдегидов с гидропероксидом трет-бутила проводили при $10 \ldots 25{ }^{\circ} \mathrm{C}$ в нейтральной среде, смешиванием эквимолярных количеств реагентов.
Вещества получили с выходом $62 \ldots 70$ \%. Синтезированные пероксиды представляли собой сиропообразные жидкости.

Замена атома водорода в карбонильном соединении на фторалкильную или фторарильную группу в ароматических кетонах значительно повышают их реакционную способность по отношению к гидропероксидам третичных алкилов, так как снижается электронная плотность на карбонильном атоме углерода, что способствует образованию гидроксигидропероксидов.

$$
\begin{aligned}
& \mathrm{Ar}_{\mathrm{F}}-\mathrm{C}(\mathrm{O})-\mathrm{R}+\underset{\left(\mathrm{CH}_{3}\right)_{3} \mathrm{COOH} \rightarrow}{\operatorname{Ar}_{\mathrm{F}}-\mathrm{CR}(\mathrm{OH}) \mathrm{OOC}\left(\mathrm{CH}_{3}\right)_{3}} \\
& \mathrm{Ar}_{\mathrm{F}}=\mathrm{C}_{6} \mathrm{~F}_{5}, \mathrm{R}=\mathrm{CH}_{3}(3), \mathrm{CF}_{3}(4), \mathrm{C}_{6} \mathrm{~F}_{5}(5)
\end{aligned}
$$

Необходимо отметить, что гидроксигидропероксиды нефторированных ароматических кетонов оказались неустойчивыми соединениями, поэтому выделить их не удалось.

При исследовании взаимодействия фторзамещенных ароматических кетонов с гидропероксидом трет-бутила, авторами было установлено, что в отличие от фторзамещенных бензальдегидов, реакция не протекает в нейтраль- 
ной среде и требуется наличие кислотного катализа. Гидроксигидропероксид на основе метилпентафторфенилкетона оказался неустойчив и при выделении разлагался. Замена метильной группы на трифторметильную или пентафторфенильную повышает устойчивость гидроксигидропероксида, что позволило их выделить, идентифицировать и определить их физикохимические константы [4-6]. Применение фторированных пероксидов в качестве инициаторов структурирования фторкаучуков показало их преимущество по сравнению с нефторированными пероксидами [7-10].

\section{ЭКСПЕРИМЕНТАЛЬНАЯ ЧАСТЬ}

ИК-спектры регистрировали на спектрофотометре Specord IR-75 в тонкой пленке для чистых маслообразных веществ, в вазелиновом масле - для кристаллических, спектры ЯМР ${ }^{1} \mathrm{H}-$ на спектрометрах Varian Mercury-300 BB (300,73 МГц) и Bruker DRX-500 (500,13 МГц), внутренний стандарт $-\mathrm{Me}_{4} \mathrm{Si}$.

1-Гидрокси-1-трет-бутилперокси(2-трифторметилфенил)метан (1).

Фторпероксид синтезировали обработкой эквимолярных количеств 2-трифторбензальдегида и гидропероксида трет-бутила при перемешивании и температуре $-15 \div 10{ }^{\circ} \mathrm{C}$. Реакционную массу выдерживали в течение 3 ч при $-5 \div 0{ }^{\circ} \mathrm{C}$. Продукты реакции подвергали вакуумированию. Очистку проводили низкотемпературным вымораживанием из петролейного эфира. Получили (I) с выходом $62 \%, \mathrm{n}_{\mathrm{D}}^{20}$ $1.4555, \mathrm{~d}_{4}{ }^{20} 1.2061, \mathrm{O}_{\text {акт. }}$ 5.89. ИК-спектр, $\sqrt{ }, \mathrm{cm}^{-1}$ : $3369(\mathrm{O}-\mathrm{H})$. Спектр ЯМР ${ }^{1} \mathrm{H}\left(\mathrm{CDCl}_{3}\right)$, $\delta$, м.д.: $1.17 \mathrm{c}\left(9 \mathrm{H}, \mathrm{CH}_{3}\right), 2.06 \mathrm{c}(1 \mathrm{H}, \mathrm{OH}), 6.36 \mathrm{c}(1 \mathrm{H}$, $\mathrm{CH}), 7.65 \ldots 8.03$ м $\left(4 \mathrm{H}, \mathrm{C}_{6} \mathrm{H}_{4}\right)$.

1-Гидрокси-1-трет-бутилпероксиперфторфенил)метан (2).

Фторпероксид синтезировали добавлением к раствору пентафторбензальдегида в тетрахлорметане эквимолярного количества гидропероксида трет-бутила при $0 \div 5{ }^{\circ} \mathrm{C}$. Реакционную смесь перемешивали при комнатной температуре в течение 2 ч. Растворитель удаляли под вакуумом. Очистку проводили низкотемпературным вымораживанием из пентана или петролейного эфира. Получили ( II) с выходом $70 \%, \mathrm{n}_{\mathrm{D}}{ }^{20} 1.4425, \mathrm{~d}_{4}{ }^{20} 1.4068, \mathrm{O}_{\text {акт }} 5.63$. ИК спектр, $\sqrt{ }$, см $^{-1}: 3429$ (О-Н). Спектр ЯМР ${ }^{1} \mathrm{H}$ $\left(\mathrm{CDCl}_{3}\right), \delta$, м.д.: $1.21 \mathrm{c}\left(9 \mathrm{H}, \mathrm{CH}_{3}\right), 2.65$ с $(1 \mathrm{H}$, $\mathrm{OH}), 6.27 \mathrm{c}(1 \mathrm{H}, \mathrm{CH})$.
1-Гидрокси-1-трет-бутилперокси-1-перфторфенил-2,2,2-трифторэтан (4). Фторпероксид (I) синтезировали по методике исследования $[14,20]$. Получили (I) с выходом $66 \%$, Т. пл. $25-26{ }^{\circ} \mathrm{C}, \mathrm{O}_{\text {акт. }}$ 4.63. ИК-спектр, $\sqrt{ }, \mathrm{cm}^{-1}: 3280(\mathrm{O}-$ $\mathrm{H})$. Спектр ЯМР ${ }^{1} \mathrm{H}\left(\mathrm{CDCl}_{3}\right), \delta$, м.д.: $1.21 \mathrm{c}(9 \mathrm{H}$, $\left.\mathrm{CH}_{3}\right), 4.29 \mathrm{c}(1 \mathrm{H}, \mathrm{OH})$.

1-Гидрокси-1-трет-бутилперокси-1,1-ди(перфторфенил)метан (5). Фторпероксид (II) синтезировали по методике исследования [4,20]. Получили (II) с выходом $90 \%$, Т пл. $65-66{ }^{\circ} \mathrm{C}$,

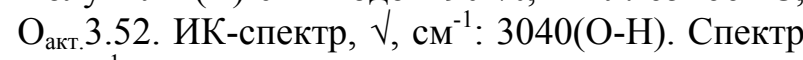
ЯMР ${ }^{1} \mathrm{H}\left(\mathrm{CDCl}_{3}\right), \delta$, м.д.: 1.19 с $\left(9 \mathrm{H}, \mathrm{CH}_{3}\right), 4.53 \mathrm{c}$ $(1 \mathrm{H}, \mathrm{OH})$.

Синтезированные гидроксигидропероксиды на основе полифторированных бензальдегидов представляют собой бесцветные сиропообразные жидкости, гидроксигидропероксиды на основе перфторированных ароматических кетонов - кристаллические вещества белого цвета. Синтезированные полифторированные гидроксигидропероксиды хорошо растворимы во многих органических растворителях -ацетоне, эфире, тетрахлорметане. Плохо растворимы в воде. Полученные пероксиды устойчивы к удару, трению, способны длительное время храниться без заметного разложения, за исключением пероксида (3), который разлагался при выделении. Индивидуальность полученных соединений подтверждали TCX на «Silufol» в системах: ацетон:толуол:гептан:тетрахлорэтан $=0.5: 1: 2: 1$; гексан:эфир $=5: 1$ и ацетон:толуол:гексан $=0.5: 1: 2$.

\section{БИБЛИОГРАФИЧЕСКИЙ СПИСОК}

1. Ольдекоп, Ю. А. Конденсация некоторых третичных гидроперекисей с ароматическими альдегидами / Ю. А. Ольдекоп, К. Л. Мойсейчук, А. П. Ювченко, А. Л. Исаханян // Весці АН БССР. Сер.хим. - 1976. - № 2. C. 105-108.

2. Чапуркин, В. В. Синтез фторзамещенных арилпероксидов / В. В. Чапуркин, Е. В. Древин // Журнал органической химии. - 1999. - Т. 35. - № 10. - С. 1580.

3. Chapurkin, V. V. Particularity primary per oxide derivative synthesis from reaction fluorinated carbonyl compounds with hydrogen peroxide./ V. V. Chapurkin, V. P. Medvedev, S. V. Chapurkin // Fluorine notes. - 2016. N 5 (108). - P. 1-2.

4. Чапуркин, В. В. О синтезе фторарилтрет-бутилкарбинолов / А. И. Рахимов, В. В. Чапуркин // Журнал органической химии. - 1978. -Т. 14. - № 4. - С. 892.

5. Чапуркин, В. В. Синтез и применение новых фторсодержащих моно- и поликарбонильных соединений и пероксидов на их основе / В. В. Чапуркин, Ю. С. Должиков, С. В. Чапуркин // Тез.докл. 9-й Всерос. конф «Химия фтоpa (F-2012)» (Москва, 2012). - С. 36.

6. Чапуркин, В. В. Получение фторсодержащих пероксидов на основе ди- и поликарбонильных соединений / 
В. В. Чапуркин, А. В. Бакланов, О. С. Леонтьева // Тез. Докл. XI Междунар. конф. по химии органических и элементоорганических пероксидов «Пероксиды 2003» (Москва, 2003). - С. 31.

7. Chapurkin, $V . V$. Features of the structure formation of fluoroelastomers by fluoroperoxides / V.V.Chapurkin, V.P. Medvedev, S.V.Chapurkin // International Polymer Science and Technology. - 2016. - T. 43. - N 2. - P. 37-40.

8. Чапуркин, В. В. Особенности структурирования фторэластомеров фторпероксидами / В. В. Чапуркин, В. П. Медведев, С. В. Чапуркин // Каучук и резина. - 2015. № 4. - C. 36-37.

9. Чапуркин, В. В. Структурирование фторэластомеров фторпероксидами / В. В. Чапуркин, В. П. Медведев, С. В. Чапуркин // Журн. приклад. химии. - 2015. - Т. 88. Вып. 8. - C. 1161-1167.DOI: 10.1134/S1070427215080091.

10. Чапуркин, B. B. Особенности сшивки фторкаучука СКФ-32 под воздействием излучения лазера / В. В. Чапуркин. С. Е. Тескер, Е. И. Тескер и др. // Высокомолекулярные соединения. Серия А и серия Б. - 2003. - Т. 45. - № 2. C. $253-257$.

11. Чапуркин, В. В. Термические и атермические превращения фторкаучука СКФ-32 под воздействием излучения лазера / В. В. Чапуркин, Ю. С. Должиков, О. Н. Кутыга, С. В. Чапуркин // Изв. вузов. Сер. Химия и химическая технология. - 2009. - Т. 52. - Вып. 4. - С. 71-74.

12. Чапуркин, В. В. Влияние фторпероксидных инициирующих агентов на свойства фторэластомерных вулканизатов / В. В. Чапуркин, В. П. Медведев, С. В. Чапуркин // научный журнал № 4 (183) / ВолгГТУ. - Волгоград, 2016. - (Серия «Химия и технология элементоорганических мономеров и полимерных материалов»). - С. 91-96.

\section{REFERENCES}

1. Oldekop, Yu.A. Condensation of some tertiary hydroperoxides with aromatic aldehydes / Yu.A. Oldekop, K.L. Moiseichuk, A.P. Yuvchenko, A.L. Isakhanyan // Vesci AN BSSR. Ser.chem. -1976. -№ 2.-P.105-108. (in Russian)

2. Chapurkin, V.V., Drevin E.V. Synthesis of fluorinated aryl peroxides / V.V.Chapurkin, E.V.Drevin // Log organ. Chemistry. -1999. -V.35. -N 10. -P.1580 (in Russian).

3. Chapurkin, V.V. Particularity primary peroxide derivative synthesis from reaction fluorinated carbonyl compounds with hydrogen peroxide / V.V.Chapurkin, V.P. Medvedev, S.V.Chapurkin //Fluorine notes. -2016. -N 5 (108). -P. 1-2.

4. Chapurkin, V.V. About the synthesis of fluoroaryl tretbutyl carbinols / A.I. Rakhimov, V.V. Chapurkin // Journal of Organic Chemistry. -1978. -V.14. -№ 4. -P. 892.(in Russian)

5. Chapurkin, V.V. Synthesis and application of new fluorine-containing mono- and polycarbonyl compounds and peroxides based on them / V.V. Chapurkin, Yu.S. Dolzhikov, S.V. Chapurkin // Abstract. 9th All-Russian. conf "Fluorine Chemistry (F-2012)" (Moscow, 2012). -P. 36. (in Russian)

6. Chapurkin, VV, Baklanov A.V., Leontieva O.S. Obtaining fluorine-containing peroxides based on di- and polycarbonyl compounds / V.V. Chapurkin, A.V. Baklanov, O.S. Leontiev // Thesis. Doc. XI Int. conf. in the chemistry of organic and organoelemental peroxides "Peroxides 2003" (Moscow, 2003). -P.31. (in Russian)

7. Chapurkin, V.V. Features of the structure formation of fluoroelastomers by fluoroperoxides /V.V.Chapurkin, V.P. Medvedev, S.V.Chapurkin // International Polymer Science and Technology. -2016. -V. 43. -N 2. -P.37-40.

8. Chapurkin, V.V. Features structuring fluoroelastomers with fluorine peroxides / V.V.Chapurkin, V.P. Medvedev, S.V.Chapurkin //Kauchuk I Rezina. -2015. -N 4. -P. 36-37 (in Russian).

9. Chapurkin, V.V. Structuring fluoroelastomers with fluorine peroxides / V.V.Chapurkin, V.P. Medvedev, S.V.Chapurkin // Log butt. Chemistry. -2015. -V. 88. -N 8. P. 1161-1167. DOI: 10.1134/S1070427215080091.

10. Chapurkin, V.V. Features of stitching fluororubber SKF-32 under the influence of laser radiation / V.V.Chapurkin, S.E.Tesker, E.I.Tesker and others// High molecular weight compounds. Series A and B. Series. -2003. V.45. -N 2. -P.253-257 (in Russian).

11. Chapurkin, V.V. Thermal and athermic transformations of fluororubber GFR-32 under the influence of laser radiation / V.V.Chapurkin, Yu.S.Dolzhikov, O.N.Kutyga, S.V.Chapurkin // Izv. universities. Ser.Chemistry and chemical technology. -2009. -V. 52. -N 4. -P.71-74 (in Russian).

12. Chapurkin V.V.Influence jf fluorine peroxide inting agenrs on the properties of fluorine elastomers vulcanizates V.V.Chapurkin, V.P.Medvedev, S.V.Chapurkin // Izvestija VolgGTU. Serija Himija I technologija jelementoor-ganichescich monomerov I polimernyh materialov Vyp.5:mezhuz. sb. Nauch.st/ VolgGTU.- Volgograd, 2016. P. -91-96.

\section{V. Chapurkin, S. V. Chapurkin \\ ABOUT THE SYNTHESIS OF 1-HYDROPEROXIDES OF FLUORO-SUBSTITUTED ARENES}

\section{Volgograd State Technical University}

Abstract. By the interaction of fluorine-substituted aromatic carbonyl compounds with tert-butyl hydroperoxide, hydroxyhydroperoxides were obtained whose non-fluorinated analogues were not obtained due to their instability. Synthesized peroxides are of interest as initiators of fluororubber structuring.

Keywords: fluorinated benzaldehydes, aromatic ketones, tert-butyl hydroperoxide, hydroxyhydroperoxide, fluororubber. 